\title{
Promoção e prevenção de Saúde do Adolescente na Atenção Primária: Implantação do Projeto - AgosTEEN
}

\section{Promotion and prevention of Adolescent Health in Primary Care: Implementation of the Project - AgosTEEN}

\author{
Promoción y prevención de la Salud del Adolescente en Atención Primaria: Ejecución del Proyecto \\ - AgosTEEN
}

\section{Scarllet Figueira Braga ${ }^{*}$, Sebastião Jorge Da Cunha Gonçalves², Thiago Augusto Soares Monteiro Da Silva ${ }^{3}$, Mônica De Almeida Carreiro ${ }^{4}$, Manoela Alves ${ }^{5}$, Margarida Maria Donato Dos Santos ${ }^{6}$}

Como citar esse artigo. Braga, SF; Gonçalves, SJCG; da Silva, TASM; Carreiro, MA; Alves, M; dos Santos, MMD. Promoção e prevenção de Saúde do Adolescente na Atenção Primária: Implantação do Projeto - AgosTEEN. Revista Pró-UniverSUS. 2021 Jan./Jun.; $12(1): 47-49$

\section{Resumo}

A pesquisa a seguir trata-se de um estudo qualitativo descritivo, focado na atenção primária a saúde dos adolescentes do município de Vassouras. Com o objetivo de identificar e refinar a qualidade de assistência dos profissionais da área da saúde. A pesquisa contou com a utilização de um questionário para delimitar as fragilidades existentes na equipe profissional do nosso município. Visto a demanda, será proposto a implementação de um projeto onde inicialmente está empenhado na capacitação dos profissionais da rede básica e posteriormente a execução do projeto vigente. Com a conclusão do presente estudo, avaliouse o atendimento e as ações ofertadas ao público adolescente, e quais as fragilidades que podemos identificar no Sistema Único de Saúde e que podem estar vindo a degradar a promoção e prevenção de saúde dos mesmos.

Palavras-chave: Adolescente; Enfermagem; Promoção da Saúde; Prevenção.

\begin{abstract}
The following research is a qualitative descriptive study, focused on primary health care for adolescents in the municipality of Vassouras. In order to identify and refine the quality of care provided by healthcare professionals. The research relied on the use of a questionnaire to define the weaknesses existing in the professional team of our municipality. In view of the demand, it will be proposed to implement a project where it is initially committed to the training of professionals in the basic network and later the execution of the current project. With the conclusion of this study, the care and actions offered to the adolescent public were assessed, and what weaknesses can we identify in the Unified Health System and which may be degrading their health promotion and prevention.
\end{abstract}

Keywords: Adolescent; Nursing; Health promotion; Prevention.

\section{Resumen}

La siguiente investigación es un estudio descriptivo cualitativo, centrado en la atención primaria de salud para adolescentes en el municipio de Vassouras. Con el fin de identificar y refinar la calidad de la atención brindada por los profesionales de la salud. La investigación se basó en el uso de un cuestionario para definir las debilidades existentes en el equipo profesional de nuestro municipio. Ante la demanda, se propondrá implementar un proyecto donde se apuesta inicialmente por la formación de profesionales en la red básica y posteriormente la ejecución del proyecto actual. Con la conclusión de este estudio se evaluó la atención y las acciones que se brindan al público adolescente y qué debilidades podemos identificar en el Sistema Único de Salud y que pueden estar degradando su promoción y prevención de la salud.

Palabras clave: Adolescente; Enfermería; Promoción de la salud; Prevención.

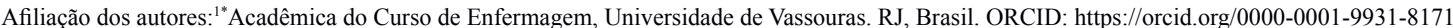

${ }^{2}$ Mestre. Docente do Curso de Enfermagem, Universidade de Vassouras. RJ, Brasil. ORCID: https://orcid org/0000-0002-4228-4641.

${ }^{3}$ Doutor em Enfermagem pela Escola de Enfermagem Anna Nery (EEAN) da Universidade Federal do Rio De Janeiro (UFRJ). Mestre em Enfermagem pela Universidade Federal do estado do Rio de Janeiro (UNIRIO), Pós graduado em Enfermagem em Oncologia Clínica pela Universidade Veiga de Almeida. Docente do curso de Enfermagem, Universidade de Vassouras. RJ,Brasil. ORCID: https://orcid.org/0000-0001-6870-5101.

${ }^{4}$ Doutora em Enfermagem. Docente do Curso de Enfermagem, Univerdade de Vassouras. RJ,Brasil. ORCID: https://orcid.org/0000-000315946491.

${ }^{5}$ Mestre em Enfermagem. Docente do curso de Enfermagem, Universidade de Vassouras. RJ, Brasil. ORCID: https://orcid.org/0000-0003-4239-9577.

${ }^{6}$ Doutora em Ciência da Saúde (UNICAMP-SP), Enfermeira em Educação Permamente (HUUFJF). Docente do Curso de Enfermagem, Universidade de Vasssouras. RJ, Brasil. ORCID: https://orcid.org/0000-0001-8681-5582 


\section{Introdução}

A adolescência, dentro do desenvolvimento humano, é a transição entre a fase infantil para a adulta, e é nesse período que ocorre o crescimento e desenvolvimento psicossocial. É importante salientar que, tanto na infância quanto na adolescência, podem ocorrer variações no padrão de velocidade de crescimento, mas não reflete na maioria dos casos uma condição patológica. Portanto, é imprescindível que as equipes de saúde acompanhem e monitorem esse processo, que pode ser influenciado por fatores ambientais e individuais. Esses fatores podem modificar, interromper ou reverter os fenômenos que caracterizam a puberdade ${ }^{1}$.

O Ministério da Saúde segue como definição de adolescência a prescrita pela Organização Mundial da Saúde (OMS)2, que caracteriza o período de 10 a 19 anos e compreende como juventude a população dos 15 a 24 anos. O Estatuto da Juventude (Lei ${ }^{\circ} 12.852$, de 5 de agosto de 2013) 3 define juventudes a partir de faixas etárias. Dos 15 a 17 anos são adolescentes-jovens; dos 18 a 24 anos de jovens-jovens e entre os 25 a 29 anos são denominados jovens-adultos.

Como as crianças e os adolescentes por vezes começam a vida sexual cedo e tendem a virar "adultos" muito precocemente, acreditamos que podemos atender os jovens de 10 à 18 anos com intuito de abordar todos os assuntos possíveis que são predominantes nessas idades.

Alguns desses temas são sexualidade, mudanças do corpo, atenção psicossocial, dentre outros, que muitas vezes é defasado pela timidez ou por estar perto dos pais. Obterão orientações, encaminhamento para outros profissionais quando necessário, e conversas dinâmicas, de fácil compreensão ${ }^{4}$.

Todas essas condutas que pretendemos implementar em nossa saúde primária, terão respaldo do ECA (Estatuto Da Criança e do Adolescente), levando em consideração as leis empregadas pelo programa nacional. Assim como o ECA tem o objetivo a proteção em tempo integral, visando o direito ao crescimento saudável e seguro, nós queremos que esse público tenha visibilidade, e autonomia de procurar a assistência na atenção básica, e receba a devida atenção da equipe multiprofissional ${ }^{5}$.

Mas, antes de dar início a tudo, foi-se necessário em primeiro lugar, delimitar as fragilidades da equipe multiprofissional do nosso município. Como esse presente trabalho, visa o curso de enfermagem, o foco principal será na equipe de enfermagem da APS. Como primeiro passo, vamos abordar o quanto essas pessoas estão entendidas sobre o assunto em relação ao público adolescente, se essas estruturas estão aptas para comportar a demanda, se a equipe já faz algum trabalho semelhante, e como isso é imposto no território. E para isso usamos um método de questionário para chegarmos a uma conclusão efetiva. Assim, após discussão, podemos propor um Plano de Assistência e Ações na Atenção Primária em Saúde (APS), voltada para os adolescentes, com o objetivo de melhorar a qualidade de assistência dessa população, visando que a APS é a porta de entrada e saída. E é de extrema importância que eles estejam oferecendo esse acolhimento para esse grupo. Organizando o cronograma semanal da APS e disponibilizando um horário para o atendimento aos adolescentes do território.

Considerando a fragilidade da equipe multiprofissional em cuidar dos adolescentes de seu território, considera-se importante que tal situação seja discutido no planejamento institucional da APS e compartilhado entre os gestores e enfermeiros, tornando possível o enfrentamento e resolutividade da problemática em questão ${ }^{6}$.

$\mathrm{O}$ estudo tem por objetivo identificar e refinar a qualidade de assistência dos profissionais da área da saúde

\section{Metodologia}

O estudo será descritivo na abordagem qualitativa, pois traz experiências dos sujeitos em um contexto social. Será realizado em seis Unidades de Estratégia Saúde da Família (UESF) da Secretaria Municipal de Saúde de Vassouras (SMSV), Rio de Janeiro. A pesquisa foi aprovada pelo Comitê de Ética em Pesquisa (CEP) da Universidade de Vassouras Número do Parecer: 3.977.844.

Os participantes da pesquisa foram 12 gestores enfermeiras da Atenção Primária em Saúde (APS), que atuam diretamente envolvidos na gestão das Unidades e no cuidado ao adolescente. Considerou-se este quantitativo conveniente, pois possibilita a profundidade das informações que serão obtidas. Estas serão coletadas por meio de entrevista semiestruturada, utilizamos como ferramenta o formulário Google Forms, seguindo roteiro com as seguintes questões: Como se dá o cuidado ao público adolescente do seu território, visando o plano assistência e gerencial em enfermagem? E como equipe multiprofissional, o quanto você acha necessário a criação e implementação de um projeto como este?

A pesquisa foi realizada no período de fevereiro a dezembro de 2020. Além do material de campo, foi necessário a leitura de artigos científicos, e cartilhas do ministério da saúde para agregar a construção e discussão do trabalho.

\section{Resultados e Discussão}


Após a elaboração do questionário, a fase de apresentar isso a equipe, foi de longe a mais fácil do projeto. Com nosso contexto atual de saúde pública, onde tantas campanhas tem vista em mídias sociais, digitais, e físicas, era de se esperar que a visibilidade do projeto fosse mais ampla. Como foi descrito a cima, contamos com uma equipe de 12 enfemeiras, e apenas 1 respondeu ao nosso questionário. $\mathrm{O}$ que se faz pensar, que existe uma resistência da equipe para lidar com esse público. Não se sabe se foi por escolha não responder, ou se não respondeu por não ter compreensão o suficiente sobre o assunto.

Como já mencionado, a fase da adolescencia é a transição para a vida adulta, é nesse momento que adquirimos os preceitos básicos para passar para outra fase. É de extrema importância que nossa saúde pública dê atenção a esse público, pois é a partir dele que podemos diminuir a incidência de problemas que vão acometer gravemente nossa população na fase adulta.

A pesquisa não obteve o alcance desejado, pois era esperado um quantativo maior de respostas, onde pudessemos de fato discutir, correlacionar conceitos, e ver o que realmente precisa no nosso município. Mas diante desse necessário, podemos extrair que a primeira barreira a ser quebrada, é esse paradgima de que o profissional de saúde se recusa a falar sobre certos assuntos. Esse tema precisa ser abordado nas APS, ele necessita ganhar visibilidade, nossos adolescentes precisam de atenção, e isso não irá acontecer, enquanto nossas equipes continuarem a agir como se o público fosse irrelevante.

\section{Conclusão}

Conclui-se que, apesar da importância do assunto abordado, ainda se tem muitos defícts na saúde do município, assim como também em contexto geral. A implementação de um projeto dessa alçada seria de bastante eficácia para acompanhamento dos adolescente. Mas isso não é possível, quando a nossa equipe multiprofissional cria resistência sobre o assunto, e isso é a primeira barreira que deve ser quebrada, antes de qualquer coisa.

No início desse trabalho, pensou-se que a maior dificuldade fosse implementar um projeto grande em um demanda especifícica, mas com o findar dele, como pesquisadora, as maiores dificuldades identificadas no periodo estudado foi a participação voluntária dos sujeitos desse desenho e de uma equipe disposta, comprometida, e com vontade de abraçar um projeto desse porte.

\section{Referências}

1. Ministério da Saúde (BR). Secretaria de Atenção à Saúde. Departamento de Ações Programáticas e Estratégicas. Proteger e cuidar da saúde de adolescentes na atenção básica [recurso eletrônico] / Secretaria de Atenção à Saúde, Departamento de Ações Programáticas e Estratégicas. Brasília (DF); 2017.

2. Organização Mundial Da Saúde (OMS). Conferência mundial sobre os determinantes sociais da saúde. Rio de Janeiro (RJ); 2011.

3. Estatuto da Juventude(BR). Estatuto da juventude: Atos internacionais e normas correlatas. - Brasília (DF); 2013.

4. Ribeiro, WA, Andrade, M, Cirino, HP, Teixeira, JM, et al Adolescência, tabaco, álcool e drogas: Uma revisão no olhar preventivo da educação em saúde na ESF. Revista Pró-UniverSUS, 2018.

5. Brasil. Casa Civil. Lei no 8.069, de 13 de julho de 1990 (BR). Dispõe sobre o Estatuto da Criança e do Adolescente e dá outras providências. Diário Oficial [da] República Federativa do Brasil, Brasília (DF); 1990. Disponível em: https:/www.gov.br/mdh/pt-br/centrais-de-conteudo/criancae-adolescente/estatuto-da-crianca-e-do-adolescente-versao-2019.pdf.Acesso em: 15/01/2021.

6. Oliveira RG. Blackbook Enfermagem. Belo Horizonte: Blackbook Editora, 2016 